\title{
The Link between the Physical and Chemical Properties of Carbon-Bearing Melts and Their Application for Geophysical Imaging of Earth's Mantle
}

\author{
FABRICE GAILLARD, NICOLAS SATOR, EMMANUEL GARDÉS, BERTRAND \\ GUILlOT, MALCOLM MASSUYEAU, DAVID SIFRÉ, TAHAR HAMMOUDA, AND \\ GUILLAUME RICHARD
}

\subsection{Introduction: Toward a Geophysical Definition of Incipient Melting and Mantle Metasomatism}

Geochemical observations on mantle xenoliths and experiments at pressure and temperature on $\mathrm{CO}_{2}$ - and $\mathrm{H}_{2} \mathrm{O}$-bearing mantle rocks have provided the widely accepted picture that melts and fluids are flowing and reacting within the solid mantle. ${ }^{1-7}$ Whether this must be seen as a transient and local process or a broad and planetary-scale mantle dynamic is unknown. ${ }^{2,4,7}$ Understanding this could establish whether these melt advection processes explain some remote geophysical observations and could help with clarifying the geodynamic roles played by these melting dynamics. The question is rendered difficult since these melts may not be easily linked to the volcanic products reaching Earth's surface; somehow, most of the mantle melting processes may produce melts that never leave the mantle and therefore remain inaccessible.

The fingerprints of such deep melts have been historically characterized by geochemical means: trace element abundances and some isotopic ratios of mantle xenoliths are modified by the reactive passage of these melts. ${ }^{2,4,6,8,9}$ Major element abundances and the modal proportions of minerals can also be significantly affected. ${ }^{6,8}$ All of this is named mantle metasomatism, ${ }^{2,8,9}$ and this process may explain some geophysical observations. ${ }^{2,10}$ Notably, mantle metasomatism has been characterized on lithospheric samples only, therefore representing the shallowest part of a deeper melting dynamic that will be presented hereafter.

The melt causing such modifications is usually not observable in mantle rocks and is also not generally found in most volcanic exposures (except for the enigmatic petit-spot volcanoes ${ }^{11}$ ). Experimental petrology has therefore been used to reconstruct the chemical compositions of the parental melt coexisting at equilibrium with the solid mantle assemblage. ${ }^{3,5,7,12,13}$ Experiments at upper-mantle conditions have shown the key role of volatile species (i.e. $\mathrm{H}_{2} \mathrm{O}$ and $\mathrm{CO}_{2}$ ) in stabilizing $\mathrm{CO}_{2}$-rich melts or fluid versus $\mathrm{SiO}_{2}$-rich melts. ${ }^{1,3,5,7,12,13}$ The take-home message of such experimental approaches is that, in the presence of volatiles, mantle melting can occur in most of the upper mantle; ${ }^{7}$ melting regions are commonly limited by redox process reactions favoring diamonds in the deep upper mantle and decarbonation reactions in the shallowest part of the mantle. $5,7,14$ 
The particularity of the mantle melting regime due the presence of $\mathrm{H}_{2} \mathrm{O}$ and $\mathrm{CO}_{2}$ is that it produces small amounts of melt (i.e. $<1 \%$ ) embedded within the solid mantle matrix. These small amounts of melt, named incipient melt, are directly linked to small amounts of $\mathrm{H}_{2} \mathrm{O}$ and $\mathrm{CO}_{2}$ (i.e. tens to thousands of part per millions (ppm)) being present in the mantle. ${ }^{15}$ These incipient melts are very $\mathrm{CO}_{2}$ and $\mathrm{H}_{2} \mathrm{O}$ rich. Their volatile-rich nature imparts physical properties to these melts that are at odds with the conventional basaltic products that reach Earth's surface. A large part of this chapter will review the state of the art on the unconventional properties of these $\mathrm{CO}_{2}-\mathrm{H}_{2} \mathrm{O}$-rich melts.

What are the origins of these melts? They are certainly diverse and linked to large-scale recycling processes, but broadly speaking, mantle convection (large or small scale ${ }^{16-18}$ ) causes decompression melting in many mantle regions. In the upper mantle, convection occurs in the asthenosphere - the convective mantle. Upwelling regions undergo decompression and produce incipient melts. The asthenosphere remains enigmatic as we do not have any mantle xenolith samples from it. Mantle xenoliths are lithospheric, being part of the plates. The mantle metasomatic processes captured from mantle xenoliths therefore describe what happens to these melts when they reach the top of the convection limbs and meet the base of tectonic plates.

The repetitive passage of small amounts of melts and their freezing and reactivity with solids can result in major geodynamic modifications. Seminal examples of reactive transports of melts within an ancient lithosphere achieving a sort of completion are reported as cases of rejuvenation. ${ }^{2,6}$ By this process, lithospheres, being thick, cold, depleted, and rigid lids, can become the warm, enriched, and soft asthenosphere. This means that the boundary between the nonconvective and the convective mantle, the so-called lithosphereasthenosphere boundary (LAB), must be partly controlled by melt advection-reaction processes. ${ }^{2,4}$ The LAB must be, at a geological timescale, a movable boundary. ${ }^{4,6}$ Notably, though this is not further discussed here, in addition to mass transfer processes, melt advection at the LAB also conveys heat (including latent heat ${ }^{19}$ ).

A critical issue is whether such small melt fractions can be detected using remote geophysical probing of the electrical conductivity (EC) and seismic properties of Earth's mantle. ${ }^{20,21}$ This requires the long-studied geochemical processes of mantle melting and metasomatism to be converted into the physical numbers that are addressed by geophysical probing. This also requires issues regarding the fluid mechanics of melt advection in the mantle to be tackled (i.e. how fast the incipient melt moves with respect to conventional convection rates and plate velocities).

Here, we address the stability domains, the atomic structures, and the physical properties of these incipient melts together with their connectivity at small-volume fractions in mantle aggregates. The objective of this assessment is to highlight the possible links between mantle melting-metasomatism and the geophysical observations that supposedly mark the LAB.

These geophysical observations indicate bright contrasts between resistive mantle lids also featuring high seismic wave velocities $\left(V_{\mathrm{P}}\right.$ and $\left.V_{\mathrm{S}}\right)$ and the underlying conductive mantle ${ }^{22,23}$ also featuring low $V_{\mathrm{S}}{ }^{23-25}$ The seismic discontinuities have been named as the 
Gutenberg discontinuity $(\mathrm{G})^{25}$ and the underlying region is the low-velocity zone (LVZ). This broad description is not a rule, as there are specific settings where such bright contrasts are not clearly observed, such as beneath cratons ${ }^{26}$ and in the enigmatic NoMelt area, ${ }^{27}$ a setting in the Pacific Ocean where no geodynamic perturbations seem to operate. We also note that the depth of this geophysical discontinuity varies from being shallow beneath oceanic plates (50-90 km) to being deep (and elusive) under cratons ( $>200 \mathrm{~km}$ ). The cause of low $V_{\mathrm{S}}$ and high conductivity remain debated; it does not have to be a unique cause, but a common explanation would be an elegant simplification. Whether these discontinuities reveal the ponding of melts is an increasingly accepted though still debated concept. ${ }^{23,25}$ Here, we will focus on the melting processes that are able to cause anomalously high ECs because the effect of melting on the genesis of the LVZ remains elusive. ${ }^{25}$

\section{2 $\mathrm{CO}_{2}$-Rich Melts in the Mantle: Stability, Composition, and Structure}

\subsubsection{Partial Melting in the Presence of $\mathrm{CO}_{2}$ and $\mathrm{H}_{2} \mathrm{O}$ : Incipient Melting}

The fluxing effect of volatiles on silicate melting has been long recognized. ${ }^{1,3,5,7,12-14}$ In the case of mantle melting, the effects of $\mathrm{H}_{2} \mathrm{O}$ and $\mathrm{CO}_{2}$, whether separately ${ }^{3,12,14,28}$ or mixed, ${ }^{1,3,7,13,29,30}$ have been investigated. It is clear that peridotite systems equilibrated with $\mathrm{H}_{2} \mathrm{O}-\mathrm{CO}_{2}$ mixtures have been poorly investigated in comparison to the (nominally) $\mathrm{CO}_{2}$-only bearing system. ${ }^{5}$

Figure 7.1 summarizes the main features for the case of melting at undersaturated $\mathrm{CO}_{2}-$ $\mathrm{H}_{2} \mathrm{O}$ fluid conditions. In the temperature region below the fluid-free high-pressure solidus, the amount of melt is controlled by the low amount of available fluid. This melting regime is incipient melting. In the incipient melting regime, several cases must be highlighted.

For pressures less than $2 \mathrm{GPa}$ (corresponding to depths of less than $60 \mathrm{~km}$ ), the solidus is weakly depressed. In this pressure range, the solubility of $\mathrm{CO}_{2}$ in silicate melts is low, most $\mathrm{CO}_{2}$ is in the fluid, and the solidus is controlled by the availability of water. ${ }^{28}$

At $\sim 2 \mathrm{GPa}$, the $\mathrm{CO}_{2}$ of the fluid reacts with the silicates, yielding carbonate mineral formation. This carbonation reaction has the effect of strongly depressing the solidus temperature, and the carbonate ledge (i.e. nearly isobaric melting curve) is developed in the phase diagram. Melts at the solidus are carbonatitic. ${ }^{1,3,7,29}$ Away from the solidus, hydrated silicate melting takes places and the melt compositions shift from carbonatitic to carbo-hydrous silicates. ${ }^{3,7,29}$ As long as the temperature remains below that of the fluidfree solidus, the amount of produced melt is controlled by the fluid availability. Major melting only happens as the fluid-free solidus is crossed (temperature $>1350^{\circ} \mathrm{C}$ at $2 \mathrm{GPa}$ ).

As pressure is further increased, the $\mathrm{CO}_{2}-\mathrm{H}_{2} \mathrm{O}$ fluid may be reduced by interaction with mantle silicates. ${ }^{3,5,13,14}$ Along the mantle geotherm, carbonate reduction following this reaction would occur at about $120-250 \mathrm{~km}$ depth. ${ }^{5,14}$ In the presence of hydrogen, a mixed $\mathrm{CH}_{4}-\mathrm{H}_{2} \mathrm{O}$ fluid is formed. ${ }^{13}$ In this fluid, water activity is lowered, resulting in increasing solidus as depth (and therefore reduction) increases. The solidus evolution caused by fluid reduction at high pressure is indicated by the dashed line with arrows in Figure 7.1. 


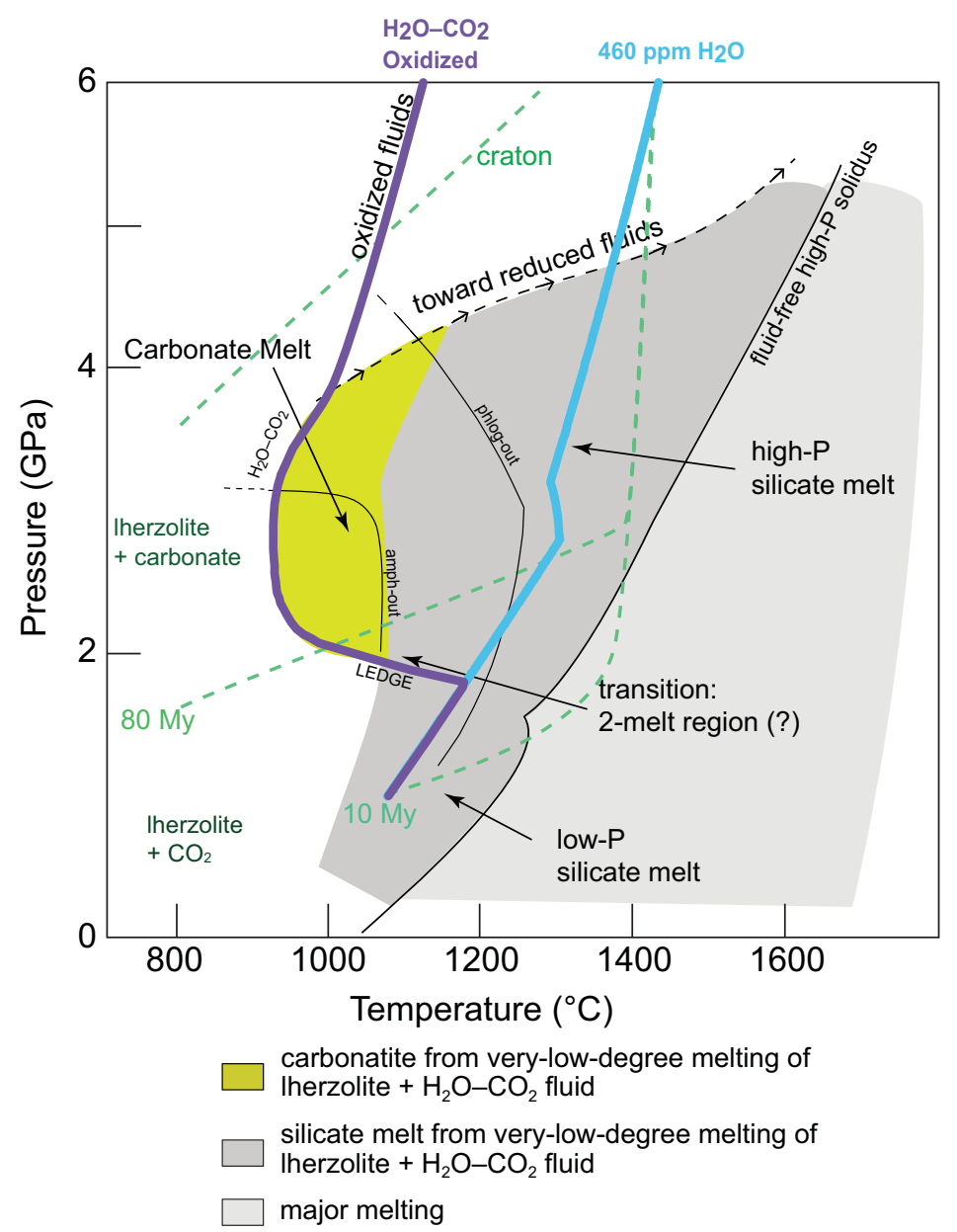

Figure 7.1 Pressure-temperature plot showing the stability fields for different types of mantle melt as a function of the volatile contents. Different geotherms (10 My, $80 \mathrm{My}$, cratons) are superimposed. The $\mathrm{CO}_{2}$-bearing hydrous peridotite solidus is calculated from the combination of solidus temperatures of Ref. 1 from 0 to $\sim 4 \mathrm{GPa}$ and Ref. 13 at higher pressures. We connected the melting curve of $\mathrm{CO}_{2}$-bearing hydrous peridotite to that of the dehydration solidus of nominally

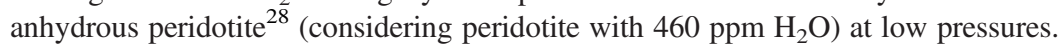

\subsubsection{Carbonate to Silicate Melts in Various Geodynamic Settings}

Following this broad picture of the process of incipient melting, we present here the range of melt compositions produced in various geodynamic settings. Two end-member cases are illustrated: adiabatic conditions showing regions where volcanism occurs at Earth's surface versus intraplate conditions showing mantle melting without volcanism.

Figure 7.2 illustrates melting along an adiabatic mantle (i.e. convective mantle) involving various $\mathrm{H}_{2} \mathrm{O}$ - and $\mathrm{CO}_{2}$-enrichments ${ }^{15}$ and a potential temperature of $1360^{\circ} \mathrm{C}$. The 

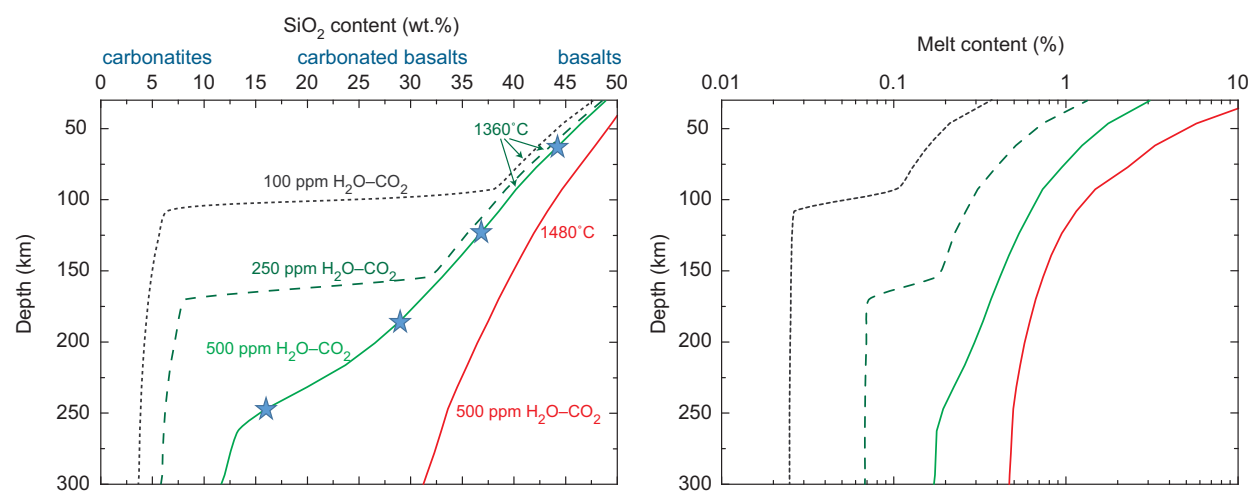

Figure 7.2 Melt composition (left) and melt fraction (right) produced during adiabatic mantle melting (temperature $=1360^{\circ} \mathrm{C}$ or $1480^{\circ} \mathrm{C}$ when specified). Under most of the pressure-temperature-volatile content conditions shown here, incipient melting occurs. Incipient melting of depleted (100 ppm $\mathrm{H}_{2} \mathrm{O}-$ $100 \mathrm{ppm} \mathrm{CO}_{2}$ ) to enriched (500 ppm) mantle sources is considered. The stars show compositions for which viscosities were determined by molecular dynamics (see Section 7.3).

calculated melts ${ }^{29}$ define an array of compositions ranging from low to high silica content in response to decompression melting: incipient melts evolving from carbonatite (i.e. $<15$ wt. $\left.\% \mathrm{SiO}_{2}\right)$, to carbonated basalts $\left(15-50\right.$ wt.\% $\left.\mathrm{SiO}_{2}\right)$, to alkali basalts $\left(\mathrm{SiO}_{2}\right.$ $>40$ wt. $\%$ ). Hereafter in the chapter, some of these compositions are used as reference compositions for which density, viscosity, and EC are defined (stars in Figure 7.2; see Section 7.3). Decreasing the bulk volatile contents decreases the absolute depth and the depth interval at which the equilibrium melt composition changes from carbonate to silicate melts: while the volatile-enriched mantle can produce silicate-bearing liquids down to $250 \mathrm{~km}$, the volatile-depleted case shows an abrupt shift in composition at $\sim 100 \mathrm{~km}$ depth within a $\sim 10-20-\mathrm{km}$ interval. This indicates that dry systems must have a greater tendency for carbonate-silicate immiscibility. Notably, Figure 7.2 does not consider the possibility of redox melting at $\sim 250 \mathrm{~km}$ depth.

Figure 7.3 illustrates the nature of equilibrium partial melts formed in an intraplate thermal regime considering both $\mathrm{CO}_{2}-\mathrm{H}_{2} \mathrm{O}$ depleted and enriched mantles. A young plate (10 Ma, red), an intermediate plate ( $80 \mathrm{Ma}$, green), and a craton (gray) are illustrated. ${ }^{31}$ These lithospheres of variable ages, and therefore variable thicknesses, can host melts with contrasting and strongly depth-dependent compositions. These lithospheres overlay a convective mantle having an age-independent pressure-temperature-melt composition pattern. The lithospheric and convective mantles are, by definition, separated by a thermal boundary layer, the LAB, separating the diffusive (lid) and the adiabatic (convective) mantles. ${ }^{31}$ To what extent discontinuities in $\mathrm{ECs}^{22,23}$ and seismic wave velocities ${ }^{25,32}$ map the depth of this thermal LAB is a matter of a great debate. The depth range of the putative seismic $\mathrm{G}$ as broadly compiled from various studies and for various geodynamic environments is shown in Figure 7.3. ${ }^{22,23}$ Notice that $G$ values are reported at depths of $\sim 60-80 \mathrm{~km}$ for oceanic 


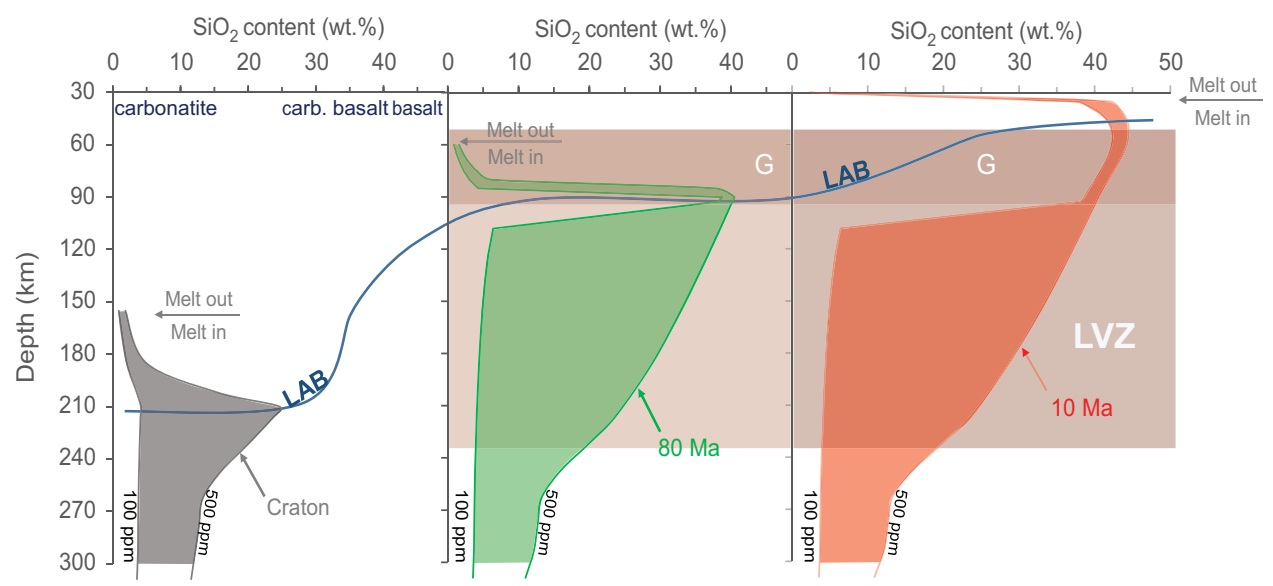

Figure 7.3 Profiles of melt compositions in intraplate geodynamic settings of variable ages (cratons, $80 \mathrm{Ma}$, and $10 \mathrm{Ma}$ from left to right) compared to the depth range of the Gutenberg discontinuity (G) and the LVZ. The curve labeled "LAB" corresponds to the thermal lithosphere-asthenosphere boundary. The LAB displays a depth that changes with the age of the plate. ${ }^{31}$ One sees that the degree of $\mathrm{H}_{2} \mathrm{O}-\mathrm{CO}_{2}$ enrichment moderately affects the type of melt composition formed at lithospheric depth. It is essentially the temperature change with depth that controls the melt composition. This narrow range of lithospheric melt compositions is at odds with the large range of melt compositions that are formed in the convective mantle, which strongly depends on the degree of $\mathrm{H}_{2} \mathrm{O}-\mathrm{CO}_{2}$ enrichment, as shown in Figure 7.2.

lithospheres of variable ages (0-120 Ma), ${ }^{23,25}$ while the conventional LAB depths for similar lithospheric ages vary over a range of $0-110 \mathrm{~km} .{ }^{31}$ We must also notice that the seismic signal of $\mathrm{G}$ may be manifold and feature variable depth-age relationships. ${ }^{32}$

The broad correspondence between the stability field of incipient melting and the geophysical signals supposed to mark the LAB has long been known. ${ }^{3,4,7,20,30,33}$ These observations must be advanced by considering the physical properties of incipient melts and how they impact the mantle rock properties near to the LAB.

\subsubsection{Structural Differences between Silicate and Carbonate Melts}

From a structural viewpoint, silicate and carbonate melts are opposites. However, they are end members of a continuum going from network-forming iono-covalent silicate liquids (e.g. silica) to ionic carbonate liquids (e.g. molten salts). The former are characterized by their degree of polymerization ${ }^{34}$ (estimated from the NBO/T ratio, with "NBO" being the number of nonbridging oxygens and " $\mathrm{T}$ " the number of tetracoordinated cations, Si and $\mathrm{Al}$ ), whereas the latter are fully depolymerized, with the liquid structure being controlled by the size ratio between anions and cations and by the ion valence state. ${ }^{35}$ The microscopic structure of silicate melts is also quantified using structural indicators such as the $Q_{\mathrm{n}}$ species (with $n=0-4$, where " $n$ " is the number of $\mathrm{TO}_{4}$ tetrahedra sharing a common 

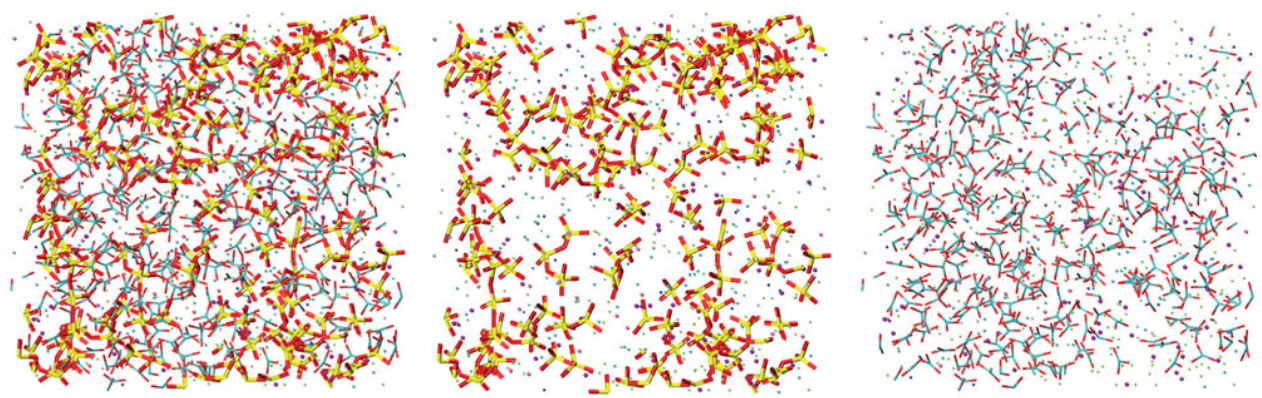

Figure 7.4 MD-generated snapshots of a carbo-silicate melt (17 wt. $\% \mathrm{SiO}_{2}$ and $28 \mathrm{wt} . \% \mathrm{CO}_{2}$ ) at $8 \mathrm{GPa}$ and $1727 \mathrm{~K}$. In the left panel, all atoms are depicted $\left(\mathrm{SiO}_{4}\right.$ in yellow and red, $\mathrm{CO}_{3}$ in cyan and red, $\mathrm{Mg}$ in green, $\mathrm{Ca}$ in cyan, $\mathrm{Na}$ in blue, $\mathrm{K}$ in pink, and $\mathrm{Fe}$ in purple, with $\mathrm{Al}$ and $\mathrm{Ti}$ not being represented for clarity reasons). In the middle panel, the carbonate ions are not depicted in order to show the silicate network, whereas in the right panel, the $\mathrm{SiO}_{4}$ units are not depicted in order to better visualize the arrangement of the carbonated component of the melt. It is clear that the $\mathrm{SiO}_{4}$ and $\mathrm{CO}_{3}$ ions do not mix well and form two subnetworks. A movie of the MD simulation may be found in the supplementary online material.

oxygen) and the coordination numbers associated with the network-forming and networkmodifying cations (e.g. $\mathrm{Nc} \approx 4$ for $\mathrm{Si}$ and $\mathrm{Al}$, and $\mathrm{Nc} \approx 5-8$ for $\mathrm{Fe}, \mathrm{Mg}, \mathrm{Ca}$, and $\mathrm{Na}$ ).

In carbonate melts, experimental and simulation studies ${ }^{35-38}$ have shown that the number of carbonate ions (playing the role of $\mathrm{O}^{2-}$ in silicate melts) around $\mathrm{Mg}$ and $\mathrm{Ca}$ is about five to six, with one oxygen of each carbonate ion pointing preferentially toward the cation (with $\mathrm{d}_{\mathrm{Mg}-\mathrm{O}}=2.0 \AA$ and $\mathrm{d}_{\mathrm{Ca}-\mathrm{O}}=2.35 \AA$, distances similar to those found in silicate melts), whereas the number of carbonate ions around each carbonate is about 12 , a value similar to the oxygen coordination number in depolymerized silicate melts. ${ }^{39}$ The selfdiffusion coefficients (D) of $\mathrm{Mg}^{2+}, \mathrm{Ca}^{2+}$, and $\mathrm{CO}_{3}{ }^{2-}$ are of the same order of magnitude, contrary to silicate melts in which the $\mathrm{D}$ values of network-forming ions (e.g. Si and O) are much smaller than those of network-modifying ions (e.g. $\mathrm{Mg}$ and $\mathrm{Ca}){ }^{40} \mathrm{In}$ carbonate melts, cations and anions exchange with each other at the same rate, preventing network formation, which is at odds with silicate melts where network formation occurs.

As a silicate component is added to a carbonate melt, recent spectroscopic studies and molecular dynamics (MD) simulations ${ }^{38,41,42}$ indicate that the carbonate ions are preferentially linked to alkaline earth cations, ${ }^{41}$ as in carbonate melts (Figure 7.4). The silicate-forming network therefore mixes poorly with the carbonate units. This atomic configuration reveals a two-subnetwork structure in carbonated basalts, reflecting a tendency to immiscibility, though this has been observed in samples quenched into clear glassy structures that do not show immiscibility. ${ }^{41,42}$ The link between a two-subnetwork atomic structure and macroscopic separation in a two-liquid system remains unclear despite its major geochemical importance. ${ }^{43,44}$ Finally, the transport properties of such a melt are difficult to predict a priori, as the silicate component implies high viscosity while the carbonate component implies low viscosity. ${ }^{45}$ 


\subsection{Physical Properties of $\mathrm{CO}_{2}$-Rich Melts in the Mantle}

\subsubsection{Evolution of the Melt Density with Composition, $\mathrm{CO}_{2}$, and $\mathrm{H}_{2} \mathrm{O}$ Contents}

It is well documented that the incorporation of both $\mathrm{CO}_{2}$ and $\mathrm{H}_{2} \mathrm{O}$ decreases the density of silicate melt. Establishing quantitative models describing this decrease as a function of the volatile content, melt composition, and pressure-temperature remains challenging, however. For illustration, we have evaluated by MD simulation the density evolution of the $\mathrm{CO}_{2}$-bearing melt $\left(\mathrm{H}_{2} \mathrm{O}\right.$ free for technical reason, since melts containing both $\mathrm{CO}_{2}$ and $\mathrm{H}_{2} \mathrm{O}$ cannot be run) along the adiabatic geotherm used in Figure 7.2. The melt composition and its $\mathrm{CO}_{2}$ content change along this adiabatic path (from a $\mathrm{CO}_{2}$-rich kimberlitic composition at $8 \mathrm{GPa}$ to a $\mathrm{CO}_{2}$-poor basaltic composition at $2 \mathrm{GPa}$ ). The resulting density-pressure path is shown in Figure 7.5 ("melt $+\mathrm{CO}_{2}$ "). For the sake of comparison, the density evolutions of two $\mathrm{CO}_{2}$-free compositions - a basalt and a kimberlite - are also reported in Figure 7.5. It is clear that, at $2 \mathrm{GPa}$, the addition of $4 \mathrm{wt} . \% \mathrm{CO}_{2}$ (to the basaltic composition) has a small effect on the melt density, whereas at $8 \mathrm{GPa}$, addition of $28 \mathrm{wt} . \%$ $\mathrm{CO}_{2}$ causes a large density drop (notice the huge density contrast between the $\mathrm{CO}_{2}$-free and $\mathrm{CO}_{2}$-bearing kimberlitic melts at $8 \mathrm{GPa}$ ). However, it is noteworthy that along the chosen thermodynamic path, the melt also contains a significant amount of $\mathrm{H}_{2} \mathrm{O}$ (from 8-9
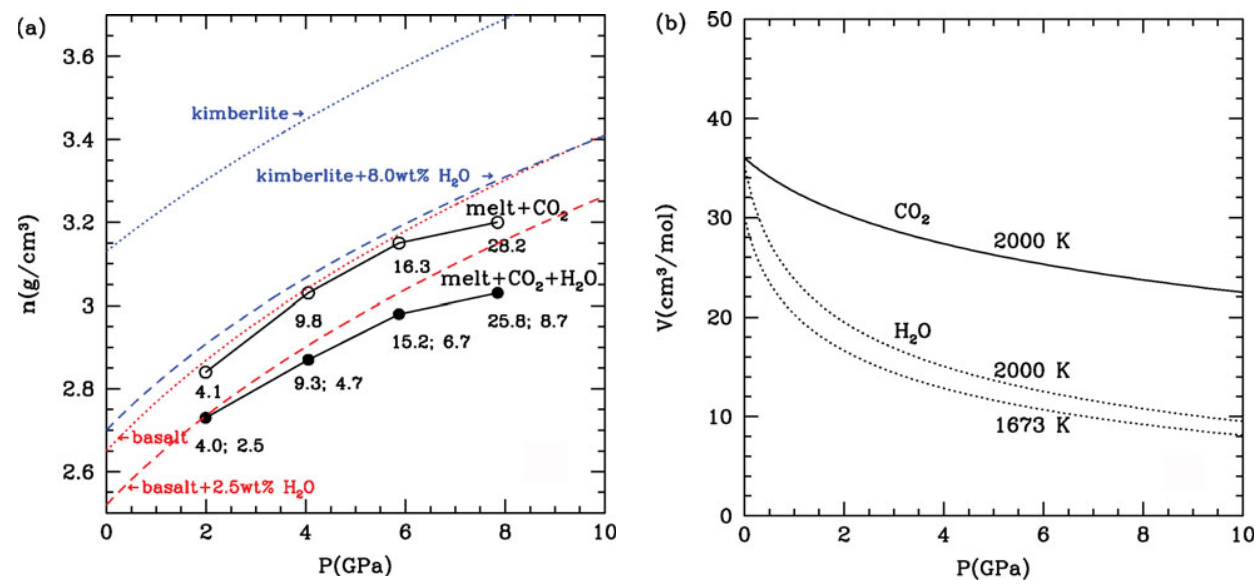

Figure 7.5 Effects of $\mathrm{H}_{2} \mathrm{O}$ and $\mathrm{CO}_{2}$ on the melt density curve as a function of pressure. (a) Calculations of melt density are performed for the melts produced along the adiabatic path of Figure 7.2. The black dots correspond to the chemical compositions marked by stars in Figure 7.2. Open symbols are $\mathrm{H}_{2} \mathrm{O}$ free and full symbols contain both $\mathrm{CO}_{2}$ and $\mathrm{H}_{2} \mathrm{O}$. Values along the line "melt $+\mathrm{CO}_{2}$ " indicate the $\mathrm{CO}_{2}$ content in wt.\%, and those along the line "melt $+\mathrm{CO}_{2}+\mathrm{H}_{2} \mathrm{O}$ " indicate the $\mathrm{CO}_{2}$ content (first number) in wt.\% and the $\mathrm{H}_{2} \mathrm{O}$ content (second number) in wt. \%. The effects of $\mathrm{H}_{2} \mathrm{O}$ content on the compressibility curve of a basaltic melt (red) and a $\mathrm{CO}_{2}$-free kimberlitic melt (blue) are given for comparison. (b) The evolution of the partial molar volumes of $\mathrm{CO}_{2}$ and $\mathrm{H}_{2} \mathrm{O}$ as a function of pressure at $2000 \mathrm{~K}$ as given by the Vinet equation of state for $\mathrm{CO}_{2}{ }^{51}$ and $\mathrm{for}_{2} \mathrm{O}^{49}$ Notice that these partial molar volumes are independent of the melt composition. The temperature dependence of $\mathrm{VCO}_{2}$ is negligible in the range 1673-2000 K. 
wt. $\% \mathrm{H}_{2} \mathrm{O}$ at $8 \mathrm{GPa}$ to $2-3$ wt. $\%$ at $2 \mathrm{GPa}$ ). We have reported in Figure 7.5 the density curve of a basaltic melt with 2.5 wt. $\% \mathrm{H}_{2} \mathrm{O}$ and of a $\left(\mathrm{CO}_{2}\right.$-free) kimberlitic melt incorporating 8 wt. $\% \mathrm{H}_{2} \mathrm{O}$. Briefly, along the chosen geotherm, the melts must be increasingly less dense with increasing pressure in comparison to conventional basaltic liquids. This yields an apparent lesser compressibility due to $\mathrm{CO}_{2}$ incorporation.

To generalize these density curves, we will assume ideal mixing between $\mathrm{CO}_{2}, \mathrm{H}_{2} \mathrm{O}$, and the silicate melt:

$$
V(T, P)=x_{\mathrm{H}_{2} \mathrm{O}} V_{\mathrm{H}_{2} \mathrm{O}}{ }^{(T, P)}+x_{\mathrm{CO}_{2}} V_{\mathrm{CO}_{2}}{ }^{(T, P)}+\left(1-x_{\mathrm{H}_{2} \mathrm{O}}-x_{\mathrm{CO}_{2}}\right) V_{s m}{ }^{(T, P)},
$$

where $V(T, P)$ is the molar volume of the volatile bearing melt, $V_{\mathrm{H}_{2} \mathrm{O}}(T, P)$ is the partial molar volume of $\mathrm{H}_{2} \mathrm{O}$ in the melt, $V_{\mathrm{CO}_{2}}(T, P)$ is the partial molar volume of $\mathrm{CO}_{2}$ in the melt, and $V_{s m}(T, P)$ is the molar volume of the volatile-free silicate melt. It has been shown ${ }^{40,46,47}$ that the assumption of ideal mixing is very accurate when only one volatile species is considered, and we will assume that this assumption still holds in the presence of both $\mathrm{H}_{2} \mathrm{O}$ and $\mathrm{CO}_{2}$.

$V_{s m}(T, P)$ is given with a very good accuracy $( \pm 1 \%)$ by a third-order Birch-Murnaghan equation of state parametrized either from density measurements ${ }^{48}$ or using MD calculations. ${ }^{39}$ For $V_{\mathrm{H}_{2} \mathrm{O}}(T, P)$, we adopt the Vinet equation of state, ${ }^{49}$ which is based on the partial molar volume data of water in various melts $\left(78\right.$ wt. $\% \mathrm{SiO}_{2}$ to 35 wt.\% $\mathrm{SiO}_{2}$, 1473-2573 K, and 1-20 GPa). Astonishingly, experimental and simulation studies ${ }^{39,47}$ show that $V_{\mathrm{H}_{2} \mathrm{O}}(T, P)$ is independent of water concentration and depends very little on the melt composition. For this reason, we can describe for any melt composition the evolution of $V_{\mathrm{H}_{2} \mathrm{O}}(T, P)$ with pressure and temperature (see Figure 7.5b). Similarly, empirical measurements and MD simulation studies ${ }^{38,40,50-53}$ show that the value for $V_{\mathrm{CO}_{2}}(T, P)$ depends very little on the melt composition, while in all these studies $\mathrm{CO}_{2}$ is found to be much less compressible than $\mathrm{H}_{2} \mathrm{O}$ in silicate melts. Changes in $V_{\mathrm{CO}_{2}}(T, P)$ along the geotherm were calculated using the Vinet equation of state. ${ }^{51}$

The density curve of the $\mathrm{H}_{2} \mathrm{O}-\mathrm{CO}_{2}$-bearing melts is shown in Figure 7.5 (see the curve entitled "melt $+\mathrm{CO}_{2}+\mathrm{H}_{2} \mathrm{O}$ "). As expected, the influence of $\mathrm{H}_{2} \mathrm{O}$ content on the density curve of the carbonated silicate melt is significant (compare the two curves with and without $\mathrm{H}_{2} \mathrm{O}$ ). We also note that the volatile-bearing melt becomes more buoyant as pressure increases.

\subsubsection{Transport Properties: Viscosity-Diffusion}

That carbonatite melts have unconventional transport properties in comparison to mantle silicate melts has long been clear to the research community, but acquiring robust quantitative data at the relevant pressure and temperature conditions has been challenging. ${ }^{35}$ The first hints were indirectly found using analyses of molten salts, ${ }^{35}$ which are well studied at atmospheric pressures by material scientists. MD have then provided insights on viscosity and diffusion properties ${ }^{54}$ at various pressures and temperatures, and Dobson et al. ${ }^{55}$ 

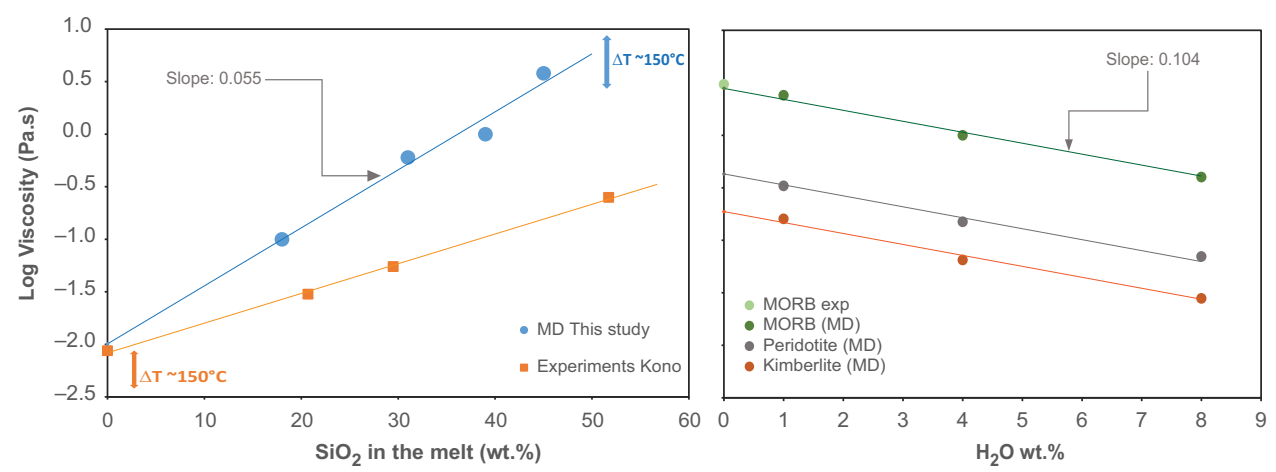

Figure 7.6 Viscosity changes as a function of melt silica content in dry carbonated melts (left) and as a function of $\mathrm{H}_{2} \mathrm{O}$ content in $\mathrm{CO}_{2}$-free melts (right). The conditions of calculation are $1400-1450^{\circ} \mathrm{C}$ and 2-8 GPa. Left: the melt compositions change from carbonatite $\left(0 \mathrm{wt} . \% \mathrm{SiO}_{2}\right)$ to basalt (45 wt.\% $\mathrm{SiO}_{2}$ ); both MD calculations (this work) and experimental measurements ${ }^{56}$ are shown. Right: the effect of water on the viscosity of silicate melts; basaltic, peridotitic, and kimberlitic melts are similarly affected by water. MORB $=$ mid-ocean ridge basalt.

provided the first in situ viscosity measurements at various pressures and temperatures. A significant step in our understanding of the transport properties of molten carbonates was realized by $\mathrm{MD}$ calculations, ${ }^{37}$ which, together with high-precision viscosity measurements, ${ }^{56}$ recently provided an internally consistent model. All of this indicates that carbonate melts have viscosity values of $\sim 0.01 \mathrm{~Pa} / \mathrm{s}$ with small to negligible temperature and melt chemical composition dependences. As these are ionic liquids in which all ionic groups move at similar rates, viscosity and ionic diffusion properties are closely linked. ${ }^{37}$ This has been made clear experimentally, ${ }^{57}$ with a remarkably simple relationship existing between the viscosity and $\mathrm{EC}$ of carbonate melts in the system $\mathrm{Na}-\mathrm{K}-\mathrm{Ca}-\mathrm{Mg}-\mathrm{CO}_{3}: \log \eta$ $=-\log \sigma$. As EC corresponds to the charge transfers due to the transport of all ionic groups, this essentially means that the ionic groups constituting carbonate melts have diffusion coefficients of $\sim 10^{-9} \mathrm{~m}^{2} / \mathrm{s}$. Notably, this also matches diffusion-limited processes such as those from melt infiltration experiments in olivine aggregates. ${ }^{58}$ This relatively wellestablished model of the transport properties of molten carbonate contrasts with our poor understanding of the physical properties of mixed carbonated basalts (e.g. kimberlites).

These findings have motivated a series of MD simulations determining the viscosity of hydrated carbonated silicate melts (Figure 7.6). The investigated compositions are those shown in Figure 7.2, and they globally correspond to a temperature range $1360-1440^{\circ} \mathrm{C}$ (pressure $=2-8 \mathrm{GPa}$; Figure 7.6). From carbonate to basalt melts, the viscosity increases by $2.5 \mathrm{log}$ units, and it follows a logarithmic relationship with the melt $\mathrm{SiO}_{2}$ content. Such variations due to changes in melt composition clearly overwhelm the expected changes due to pressure and temperature ( $\Delta \mathrm{T}$ of $150^{\circ} \mathrm{C}$ implies a change in basalt viscosity of $\sim 0.5 \mathrm{log}$ units). We noticed that the calculated viscosity change from carbonate to basalt melts 
exceeds that which has been experimentally determined. ${ }^{56}$ This is not surprising since Kono et al. ${ }^{56}$ considered $\mathrm{CaSiO}_{3}$ melts as silicate melt end members instead of basalts (i.e. Al-bearing systems) in our case. Interestingly, we notice that the logarithmic relationship still holds, but the slope differs. The effect of water has been addressed for three different $\mathrm{CO}_{2}$-free compositions (basalt, peridotite, and kimberlite) and it also shows a logarithmic relationship. The magnitude of the viscosity change due to water incorporation in the melt is much less than that described upon changing from carbonate to basalt, but an important point is that the effect of water is independent of the melt chemical composition: addition of 1 wt. $\% \mathrm{H}_{2} \mathrm{O}$ decreases the melt viscosities by $\sim 0.1 \mathrm{log}$ units for all melt compositions. This implies that the following relationship can describe the viscosity changes of hydrated melts having a composition between carbonate $\left(0 \mathrm{wt} . \% \mathrm{SiO}_{2}\right)$ and basalts $\left(45 \mathrm{wt}\right.$. $\left.\% \mathrm{SiO}_{2}\right)$ :

$$
\log \eta( \pm 0.2)=\left[0.055 \times \mathrm{SiO}_{2}(\mathrm{wt} \%)\right]-2.00-\left[0.104 \times \mathrm{H}_{2} \mathrm{O}(\mathrm{wt} \%)\right] .
$$

In this relationship, notice that the effects of pressure and temperature are neglected. These effects were determined in basalts, ${ }^{59}$ but the above equation quantifies an effect of melt chemical compositions being much greater than the expected pressure-temperature effects (see arrows in Figure 7.6).

\subsubsection{Electrical Conductivity}

The EC of mantle melts is an important geophysical property as it may guide the interpretation of magnetotelluric data. Conductivities in specific regions of Earth's mantle reaching or exceeding $0.1 \mathrm{~S} \mathrm{~m}^{-1}$ have long been considered as anomalously high. Several interpretations are possible, including water in olivine ${ }^{60}$ (which is, however, a controversial issue ${ }^{61}$ ), hydrated basalts, ${ }^{62}$ and carbonatite. ${ }^{21}$ Carbonatite melts and hydrated basalts are not singular geological objects, but they constitute end-member products of incipient melting. ${ }^{30}$ Carbonated basalts, constituting intermediate compositions between carbonatites and hydrated basalts, form the dominant melt compositions featuring incipient melting. Incipient melting could therefore be mapped from mantle EC, offering the exciting prospect of a direct visualization of the deep carbon and water cycles using geophysical data. This has motivated several recent experimental and theoretical surveys. ${ }^{33,36,37,57,62-65}$ A summary of these surveys is shown in Figure 7.7, delineating the conductivity-temperature domains for dry and hydrated basalts, kimberlites, and carbonatites. Carbonatites at mantle pressure and temperature have conductivities exceeding $200 \mathrm{~S} \mathrm{~m}^{-1}$, while carbonated basalts (e.g. kimberlites) are in the range 30-200 $\mathrm{S} \mathrm{m}^{-1}$. Sifré et al. ${ }^{33}$ proposed a model describing the changes in conductivity as the melt chemical composition evolves from carbonate to basalt melts:

$$
\sigma_{\text {model }}=\left(\sigma_{0}^{\text {basalt }} \times \exp \left(\frac{-E_{a}^{\text {basalt }}}{R T}\right)\right)+\left(\sigma_{0}^{\mathrm{CO}_{2}} \times \exp \left(\frac{-E_{a}^{\mathrm{CO}_{2}}}{R T}\right)\right) .
$$



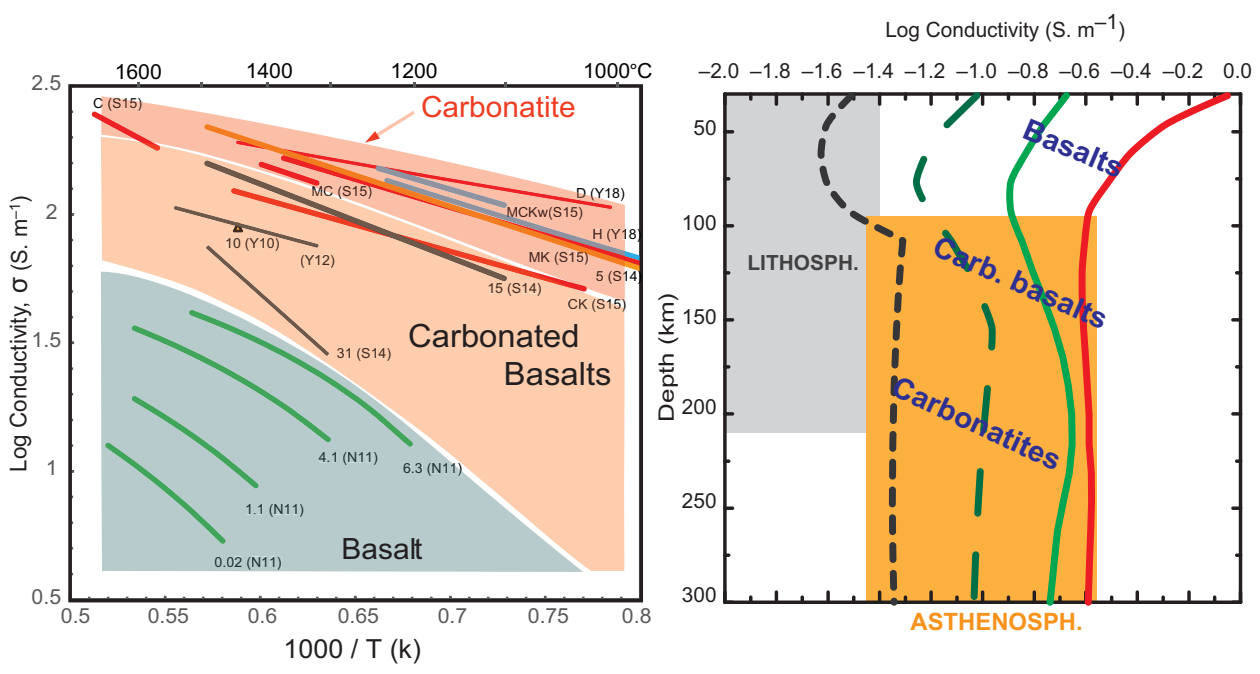

Figure 7.7 The EC of incipient melts either pure (left) or embedded into a olivine matrix (right). (Left) Basalts, kimberlites, and carbonatites are shown. The basalts are labeled in terms of water contents. ${ }^{62}$ The kimberlite are labeled in terms of $\mathrm{CO}_{2} .{ }^{33,63,64}$ Carbonatite melts are compiled from Refs. 33, 57, 65. (Right) The conductivity of the mantle during incipient melting. The four cases from Figure 7.2 are converted here into EC versus depth signals. The solid mantle is approximated by hydrated olivine using the model of hydrated olivine. ${ }^{85}$ The melt conductivity is calculated from Ref. 33. Values of $0.1 \mathrm{~S} \mathrm{~m}^{-1}$ are identified by the magnetotelluric community as anomalies.

Figure 7.7 shows the effect of incipient melting on the conductivity of mantle rocks along the adiabatic path of Figure 7.2. It shows that the depleted mantle produces moderately high ECs $\left(<0.1 \mathrm{~S} \mathrm{~m}^{-1}\right)$, while the enriched mantle produces conductivities that match or exceed most geophysical assessments $\left(>0.1 \mathrm{~S} \mathrm{~m}^{-1}\right)$. Given that the mantle source of mid-ocean ridge basalts (MORBs) varies in $\mathrm{CO}_{2}$ content from 20 to $1200 \mathrm{ppm}$, this implies that mantle ECs may vary by greater than an order of magnitude.

\subsection{Interconnection of $\mathrm{CO}_{2}$-Rich Melts in the Mantle}

Carbonate melt-olivine wetting angles $\theta$ were found to range narrowly around $30^{\circ}$ $\left(23-36^{\circ}\right)$ over various experimental conditions $\left(1200-1400^{\circ} \mathrm{C}, 0.5-3.0 \mathrm{GPa}, \mathrm{CaMg}\left(\mathrm{CO}_{3}\right)_{2}\right.$, $\mathrm{Na}_{2} \mathrm{CO}_{3}, \mathrm{~K}_{2} \mathrm{CO}_{3}$, and $\mathrm{CaCO}_{3} \pm \mathrm{H}_{2} \mathrm{O}$ carbonate compositions). ${ }^{66,67}$ Thus, similarly to silicate melts, carbonate melts have $<60^{\circ}$ wetting angles. This implies that they should form interconnected networks at any melt fractions according to theories of melt equilibrium distribution. ${ }^{68}$ This has consequences for transport properties in mantle rocks.

One of the most employed and powerful tools for investigating melt interconnectivity is in situ EC measurement in high-pressure and high-temperature apparatus. EC measurements provide bulk electrical responses of partially molten samples at mantle conditions. In situ measurements are also of particular importance for carbonated melts since they are 

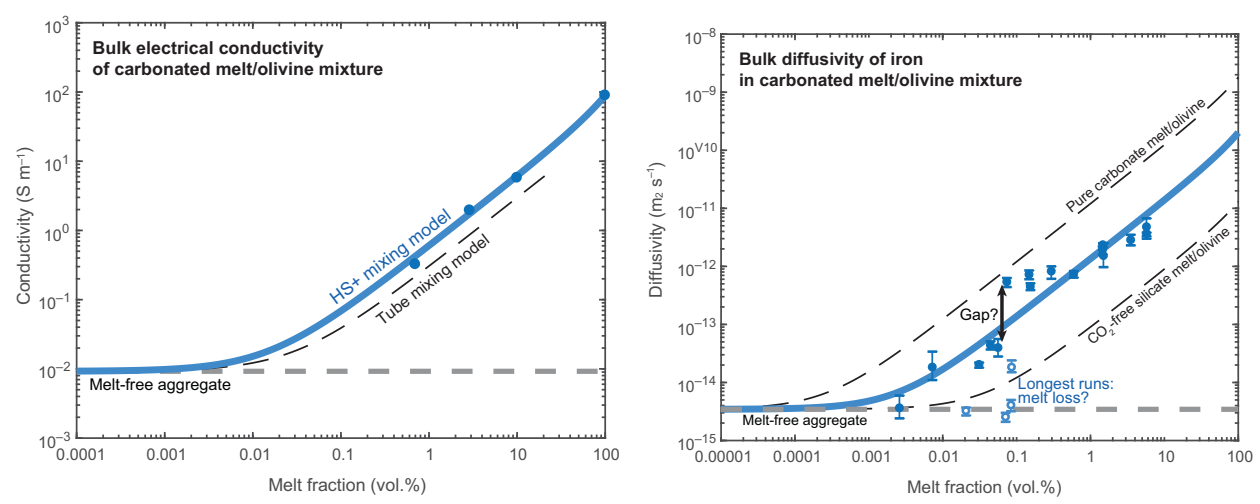

Figure 7.8 Evidence for interconnectivity at small melt fractions within olivine aggregates. (Left) Bulk EC of a carbonated melt/olivine mixture, evidencing melt interconnection over the range of investigated melt fractions down to 0.7 vol. $\%$. Experimental data ${ }^{63}$ (blue circles) were collected at $1377^{\circ} \mathrm{C}$ and $3 \mathrm{GPa}$. The HS+ mixing model (7.4) does reproduce the data very well, while the tube mixing model (7.5) appears inappropriate. Models were calculated (no adjustments) using $\sigma_{\text {melt }}=$ $8.91 \times 10^{1} \mathrm{~S} \mathrm{~m}^{-1}$ (conductivity at $100 \%$ melt) and $\sigma_{\text {solid }}=9.23 \times 10^{-3} \mathrm{~S} \mathrm{~m}^{-1}$ (olivine conductivity at $1377^{\circ} \mathrm{C}$ ). ${ }^{85}$ (Right) Bulk diffusivity of iron in a carbonated melt/olivine mixture evidencing melt interconnection down to very small melt fractions $<0.01 \mathrm{vol} . \%$. Experimental data ${ }^{70}$ were obtained at $1300^{\circ} \mathrm{C}$ and $1 \mathrm{GPa}$. Runs with longest durations (95-127 hours, empty blue circles) are differentiated from the other runs (5-49 hours, full blue circles), since they were possibly affected by melt loss (see text). Data roughly follow a trend that is intermediate between the bulk diffusivities of pure molten carbonate/olivine mixture and of a $\mathrm{CO}_{2}$-free molten silicate/olivine mixture (dashed curves). The gap at $\sim 0.07 \mathrm{vol} . \%$ melt, if significant, might mark a transition from tube to HS+ types of interconnection. The dashed curves are HS+ mixing laws with $D_{\text {melt }}=1.8 \times 10^{-9} \mathrm{~m}^{2} \mathrm{~s}^{-1}$ for pure a molten carbonate/ olivine mixture ${ }^{37}$ (diffusivity of $\mathrm{Ca}$ in $\mathrm{CaCO}_{3}$ at $1300^{\circ} \mathrm{C}$ and $1 \mathrm{GPa}$ ) and $\mathrm{D}_{\text {melt }}=1.3 \times 10^{-11} \mathrm{~m}^{2} \mathrm{~s}^{-1}$ for a $\mathrm{CO}_{2}$-free molten silicate/olivine mixture (diffusivity of $\mathrm{Fe}$ in basaltic melt at $1300^{\circ} \mathrm{C}$ and $1 \mathrm{~atm}$ ), where the diffusivity in a melt-free solid matrix is given by runs with no added carbonate, ${ }^{70} \mathrm{D}_{\text {solid }}=$ $3.45 \times 10^{-15} \mathrm{~m}^{2} \mathrm{~s}^{-1}$. The blue curve is an adjustment of the experimental data with a HS+ mixing law. The added carbonate weight fractions reported by Ref. 70 were converted to the melt volume fractions using conversion factors of $\sim 1.5$.

hardly quenchable, and thus post mortem characterizations may be misleading. In situ EC measurements were measured at $1377^{\circ} \mathrm{C}$ and $3 \mathrm{GPa}$ on mixtures of olivine and dolomitic melts with $~ 10-20$ wt. $\% \mathrm{SiO}_{2} .{ }^{63}$ Measured bulk conductivities are significantly enhanced compared to melt-free solid conductivities over the range of investigated melt fractions (down to $0.7 \mathrm{vol} . \%$ ). As illustrated in Figure 7.8, the data are remarkably well reproduced by the Hashin-Shtrikman upper-bound (HS+) model:

$$
\sigma_{\text {bulk }}=\sigma_{\text {melt }}+(1-\varphi)\left(\frac{1}{\sigma_{\text {solid }}-\sigma_{\text {melt }}}+\frac{\varphi}{3 \sigma_{\text {melt }}}\right)^{-1},
$$

where $\varphi$ is the melt volume fraction, $\sigma_{\text {melt }}$ and $\sigma_{\text {solid }}$ are the conductivities of melt and solid end members, respectively, and $\sigma_{\text {bulk }}$ is the conductivity of the mixture. 
This result is rather unexpected since the HS+ model considers a liquid-solid system where the liquid completely wets the matrix grains (no solid-solid contact), which is for $\theta=0^{\circ}$ according to melt equilibrium distribution theories. For systems with $0^{\circ}<\theta<60^{\circ}$ (i.e. where interconnections occur via tubules along grain edges), the tube mixing model is expected:

$$
\sigma_{\text {bulk }}=\frac{1}{3} \varphi \sigma_{m e l t}+(1-\varphi) \sigma_{\text {solid }}
$$

However, this model does not reproduce the experimental data (Figure 7.8). ${ }^{63,64}$ This highlights at least three points: (1) the wetting angles could have been overestimated and grain boundary wetting overlooked; ${ }^{69}$ (2) some of the simplifying assumptions of melt equilibrium distribution theories (e.g. equally sized spherical grains, no anisotropy) might significantly depart from actual systems; and (3) the tube model might underestimate the conductivity of actual melt-solid geometries and the HS+ model might also, though fortuitously, apply to tubular melt distributions.

Evidence for the interconnection of $\mathrm{CO}_{2}$-bearing melts down to very small fractions has been provided using "diffusion-sink" experiments in the $\mathrm{Na}_{2} \mathrm{CO}_{3}$-olivine system at $1300^{\circ} \mathrm{C}$ and $1 \mathrm{GPa}$ with carbonate additions as low as $\sim 0.001 \mathrm{wt} . \% .^{70}$ In these experiments, iron is lost from olivine and diffuses via the molten intergranular medium into a platinum sink placed at the top of the sample as a proxy for melt interconnectivity. Figure 7.8 illustrates the iron bulk diffusivities as a function of melt fractions. In Figure 7.8, we converted added $\mathrm{Na}_{2} \mathrm{CO}_{3}$ weight content to the melt volume fraction by taking into account that the melt dissolves $\sim 30$ wt.\% olivine ( 14 wt. $\% \mathrm{SiO}_{2}$; weight to volume fraction conversion factors of $\sim 1.5) .^{70}$ The striking point is that significant diffusivity enhancement occurs down to below 0.01 vol.\% melt. We have to highlight here that our interpretation differs from that of Minarik and Watson, ${ }^{70}$ who concluded that carbonated melt interconnectivity stops at $0.03-0.07 \mathrm{wt} . \%$ added carbonate $(\sim 0.04-0.10$ vol.\% melt). They based their conclusion on the fact that the longest experiments (95-127 hours) do not yield increases in bulk diffusivities (Figure 7.8), while they are the most likely to reach textural equilibrium. However, millimetric melt migrations can be achieved in less than 1 hour in the $\mathrm{Na}_{2} \mathrm{CO}_{3}$-forsterite system at $1300^{\circ} \mathrm{C}$ and $1 \mathrm{GPa}$, with a melt distribution along grain edges consistent with textural equilibrium. ${ }^{58}$ Thus, the shortest experiments (5 hours) of Minarik and Watson ${ }^{70}$ were very likely all texturally equilibrated. Conversely, it is possible that some melt was lost from the charges into the surrounding graphite medium in the longest experiments. When ignoring the four longest runs (95-127 hours), the remaining runs (5-49 hours) roughly follow a trend that is intermediate between the bulk diffusivities of pure molten carbonate/olivine mixing and that of $\mathrm{CO}_{2}$-free molten silicate/ olivine mixing. There might be a gap at $\sim 0.07$ vol. $\%$ melt, which requires corroborations, but it is not an interconnection stoppage, since bulk diffusivity enhancement is still observed down to 0.007 vol. $\%$.

To sum up, wetting angle measurements indicate that $\mathrm{CO}_{2}$-rich melts should form interconnected networks at any melt fraction in mantle rocks according to melt equilibrium 
distribution theories. This is validated by experiments down to below 0.01 vol. \% melt. No interconnection stoppage can be clearly evidenced. The lowest melt fraction so far investigated in silicate melt/mantle rock systems (i.e. 0.15 vol.\%) also reveals conductivity enhancement. ${ }^{71}$ From 100 down to $\sim 1$ vol. $\%$ melt, the bulk transport properties of carbonated melt-bearing mantle rocks (e.g. EC, mass transfer, etc.) can be calculated using the HS+ mixing model. Whether the HS+ model still applies down to very small melt fractions $(<0.01 \%)$ remains to be elucidated. These results stem from experiments using high-pressure apparatus where grain size is typically in the order of $\sim 10 \mu \mathrm{m}$. Both melt interconnectivity and melt wetness increase as a function of grain size, ${ }^{70,72}$ and thus should be strongly enhanced by millimetric grain sizes in the mantle.

\subsection{Mobility and Geophysical Imaging of Incipient Melts in the Upper Mantle}

\subsubsection{Melt Mobility as a Function of Melt Composition}

Knowledge of melt compositions and their viscosities (Sections 7.2 and 7.3) and evidence for their interconnection at very small melt fractions (Section 7.4) allow us to estimate the mobility of small fractions of $\mathrm{CO}_{2}$-rich melts in the upper mantle. The mobility of a fluid embedded in a solid matrix is commonly addressed using the well-known Darcy's law. According to Darcy's law, the melt mobility is due to buoyancy $(\delta \rho g)$ and is favored by low viscosity of the fluid $\left(\eta_{f}\right)$ and high permeability $(k(\Phi))$ :

$$
V=\frac{k(\Phi)}{\eta_{f}} \delta \rho g .
$$

In the case of mantle incipient melting and metasomatism, permeability goes down to very small values. Viscosity of the liquids increases by more than two orders of magnitude as the melt changes from carbonatite to basalt (Figure 7.7), while density variations are moderate (at $2 \mathrm{GPa}$, density changes from 2.4 to $2.8 \mathrm{~g} \mathrm{~cm}^{-3}$ from carbonatite ${ }^{36}$ to basalt $\left.{ }^{34,47,49,59}\right)$.

Permeability is related to the degree of melting (porosity) as:

$$
k(\Phi)=\frac{d^{2}}{C} \Phi^{n},
$$

where $d$ is the grain size, $\Phi$ is the melt fraction (variable), and the parameters $C$ and $n$ are empirical values.

Here, we address the mobility of three types of incipient melts: carbonatites, carbonated basalts, and hydrated basalts. We assume a mantle grain size of $1 \mathrm{~mm}$ and we use an experimental permeability law ${ }^{73}$ that is based on observations of samples with basaltic melt contents in the range of $1.5-18.0 \mathrm{vol} . \%(C=58$ and $n=2.6)$. We therefore operate an extrapolation toward much smaller melt fractions, which is justified in Section 7.4.

As is shown in Figure 7.9, carbonatites are very mobile, reaching velocities in the order of centimeters per year, even at melt fractions as low as 0.1 vol.\% (typical of mantle 


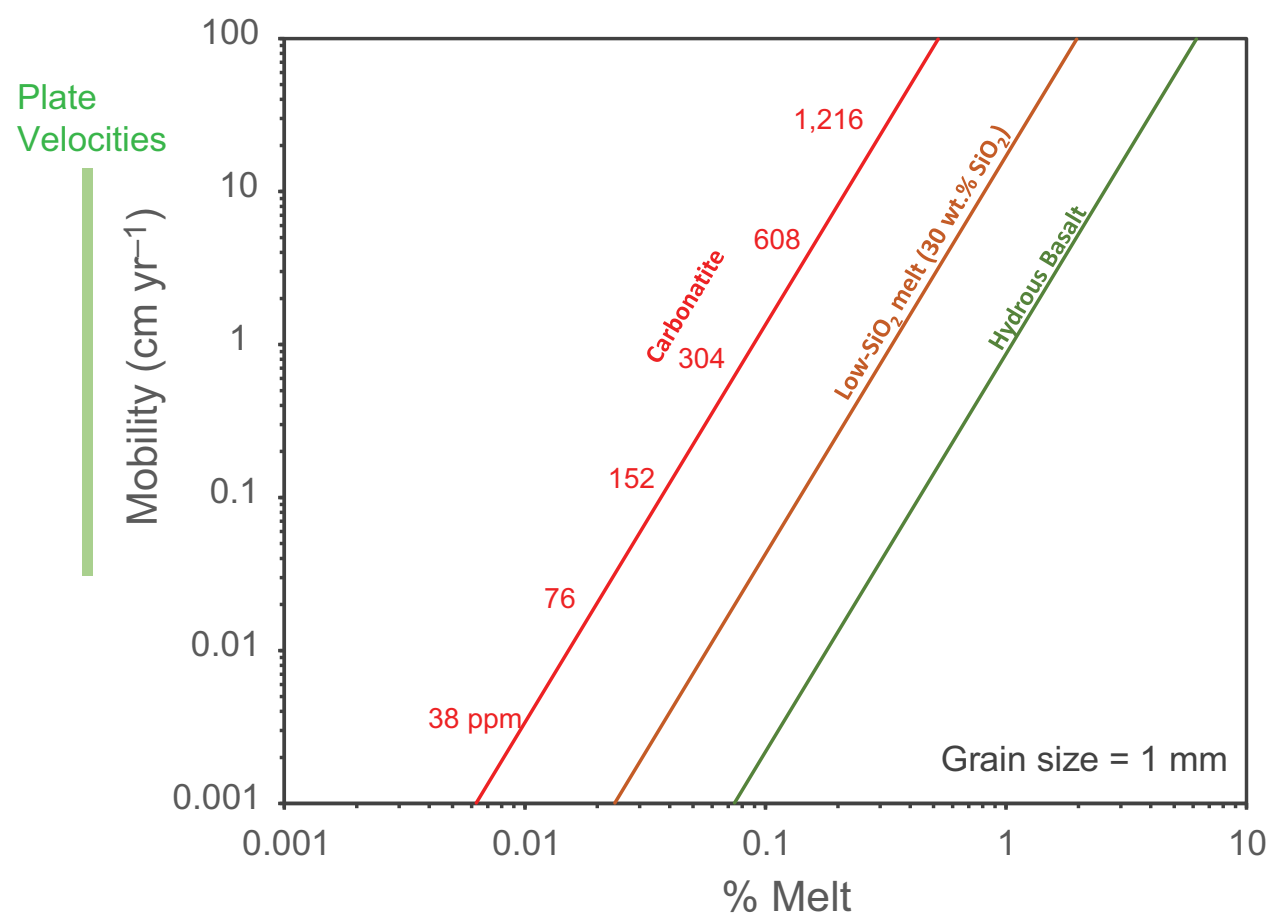

Figure 7.9 The melt vertical velocity at mantle depth versus melt fractions during incipient melting. Carbonatites, carbonated basalts, and hydrated basalts are shown. Carbonatites (containing $40 \mathrm{wt} . \%$ $\mathrm{CO}_{2}$ ) are labeled in equivalent ppm $\mathrm{CO}_{2}$ contents in the bulk rock. This concentration range covers depleted to enriched MORB sources. ${ }^{15}$ The basalt contains 2 wt. $\% \mathrm{H}_{2} \mathrm{O}$ and 0.2 wt. $\% \mathrm{CO}_{2}$, while the carbonated basalt contains 2 wt. $\% \mathrm{H}_{2} \mathrm{O}$ and 15 wt. $\% \mathrm{CO}_{2}$.

metasomatism ${ }^{2,4,6-8}$ ). Hydrated basalts can move as fast as carbonatites when they have at ten times greater melt fractions (i.e. 1 vol.\% hydrated basalt moves as fast as 0.1 vol.\% carbonatites). A velocity of $1 \mathrm{~cm} \mathrm{yr}^{-1}(0.1 \%$ of carbonatite melt) is high, but this only corresponds to $10 \mathrm{~km}$ of ascent within 1 Myrs. Nevertheless, ten times greater velocities are reached at $0.2-0.3 \%$ carbonatite. Furthermore, compaction processes, which are not considered here, must enhance the melt velocities. ${ }^{19}$ This simple analysis implies that carbonatites can be efficient metasomatic agents operating over long distances at geological timescales, as has been suggested many times. ${ }^{2,4,6,7,9,58}$ Hydrated basalts can have similar metasomatic roles if present at melt fractions exceeding 2-3\%.

In the most depleted mantle sources containing $<100 \mathrm{ppm} \mathrm{CO}_{2}$, incipient melts are not mobile due to too small melt fractions (i.e. $<0.02$ vol.\% carbonatite). In contrast, carbonatite melts formed in the most enriched mantle are very mobile $\left(>10 \mathrm{~cm} \mathrm{yr}^{-1}\right)$. Such a high mobility implies that these melts would rapidly migrate and would hardly be preserved if in physical contact with their source. This also implies unavoidable mixing processes in the column of melting where deep incipient melts rise fast and mix 
with upper-mantle regions (Figures 7.2 and 7.3), where melts produced at $200 \mathrm{~km}$ depth would rise fast and mix with the melts produced at shallower levels. The radioactive disequilibria found in MORBs have already been interpreted considering these mixing processes, ${ }^{74}$ but how they impact the highly variable $\mathrm{CO}_{2} / \mathrm{Nb}$ ratios of MORBs ${ }^{15}$ remains unaddressed.

\subsubsection{EC versus Mobility of Incipient Melts}

The identification of the exact nature of the melts responsible for high EC anomalies in the mantle is critical. It would allow us to decipher whether these electrical anomalies reflect lithospheric processes, being cold and involving carbonatites, or asthenospheric processes, being warm and involving (hydrated) basalts. If the electrical anomalies result from carbonated basalt (low- $\left.\mathrm{SiO}_{2}\right)$ melts, they may indicate both asthenospheric and lithospheric processes, since these melts can be stable in both domains (see Figure 7.3).

We calculate that incipient melting of a peridotite can produce an electrical anomaly $\left(\sim 0.1 \mathrm{~S} \mathrm{~m}^{-1}\right)^{22,23,27,75}$ if it contains $0.1 \pm 0.04 \%$ of carbonatite melts, $0.3 \pm 0.15 \%$ of carbonated basalts, or $1-6 \%$ of hydrated basalts at $1350^{\circ} \mathrm{C}$ and $3 \mathrm{GPa}$ (Figure 7.10). Note that the calculation is only weakly dependent on temperature given the low temperature dependence of the EC of incipient melts (Figure 7.7).

The comparison of Figures 7.3 and 7.10 indicates that electrical anomalies in a young plate $(<10 \mathrm{Ma})$ at $\sim 80 \mathrm{~km}$ depth $^{23}$ can reasonably be matched with hydrated basalts, ${ }^{62}$ while deeper anomalies observed beneath older plates (i.e. $>50 \mathrm{Ma})^{23,75}$ may match any kind of $\mathrm{CO}_{2}$-rich melt. ${ }^{33}$

The mobility of melts produced during incipient melting conditions matching a conductivity of $0.1 \mathrm{~S} \mathrm{~m}^{-1}$ are reported in Figure 7.10. Both carbonatite and the hydrated basalt cases yield the highest velocities, favoring melt extraction, while carbonated basalts (low$\mathrm{SiO}_{2}$ melts) yield minimum velocities, favoring melt stability. Whether melts can be stabilized and detected by geophysical means therefore depends on the convection velocity of the mantle sourcing the melts. Highly mobile melts such as $>0.1$ vol.\% carbonatite or 3 vol. \% basalts can be detected in settings with mantle velocities of $\sim 10 \mathrm{~cm} \mathrm{yr}^{-1}$ or more (e.g. the center of mantle plumes feeding volcanic hotspots such as $\mathrm{Hawai}^{76}$ or the East Pacific Rise $^{23,77}$ ).

Away from these extreme geodynamic settings, many types of convections can occur in the mantle at rates in the range $0.1-1.0 \mathrm{~cm} \mathrm{yr}^{-1} \cdot{ }^{16,17,19}$ There, the most likely type of incipient melts producing high conductivity are carbonated basalts. These melts contain $30-40$ wt. $\% \mathrm{SiO}_{2}$, implying that their viscosity is close to that of basalt but with enhanced $\mathrm{EC}$, as their $\mathrm{CO}_{2}$ contents are $\sim 10-20 \mathrm{wt} . \%$. About $0.3 \pm 0.15 \%$ of such melts are required to produce high EC. This corresponds to $180-440 \mathrm{ppm} \mathrm{CO}_{2}$ in the mantle. Notably, these melts resemble petit-spot volcanism. ${ }^{1,78}$ These $\mathrm{CO}_{2}$-rich melts are believed to remain in the mantle beneath plates and to be extracted when particular stress regimes just ahead of subduction zones trigger diking at a lithospheric scale. ${ }^{11}$ 


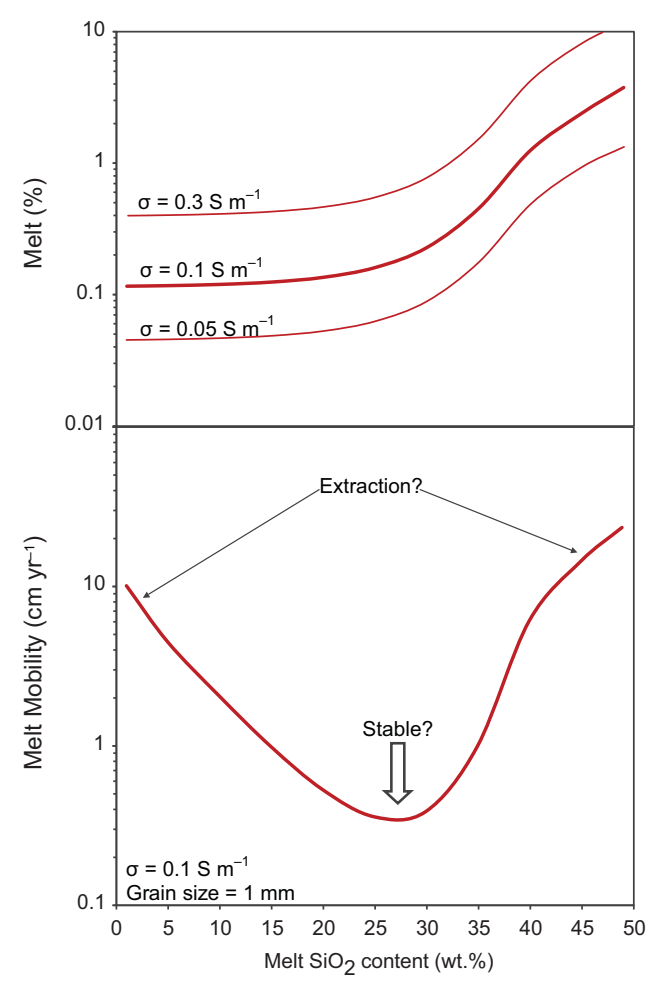

Figure 7.10 Incipient melting conditions producing high EC and the corresponding melt mobility. (Top) The range of melt fraction-melt compositions producing high ECs; three curves corresponding to three values of conductivity are shown. (Bottom) The mobility of incipient melt at the melt content required to produce high EC. A minimum in melt mobility appears in the case of carbonate basalts, while carbonatites and hydrated basalts are very mobile.

\subsection{Conclusions}

Due to the presence of small amounts of $\mathrm{CO}_{2}$ and $\mathrm{H}_{2} \mathrm{O}$ in Earth's mantle, incipient melting can occur in the regions close to the LAB. The produced melts have unconventional physical properties such as low densities, low viscosities, high diffusion rates, and high ECs, but there are strong interplays between the chemical compositions and physical properties of these melts. In a melting column (e.g., in ridges (Figure 7.2) or intraplates (Figure 7.3)), the structural composition of the produced incipient melts greatly changes from ionic to polymerized as a function of depth. This must cause a series of extractionaccumulation processes, so far unidentified, which are critical in our interpretation the geophysical and geochemical fingerprints of magmatism. Notably, these incipient melts remain interconnected even at very small melt fractions. This implies that a broad distribution of interconnected incipient melts can impact geophysical observations. On the other hand, interconnected low-viscosity melts also mean high melt mobility, which speaks 
against their stability within their source regions. In particular, for the incipient melting conditions capable of producing geophysical anomalies, melt extraction must occur rapidly at a geological scale. Production-extraction of incipient melts must therefore be considered altogether within the convective mantle.

\subsubsection{LAB versus Geophysical Discontinuities}

The LAB is a concept assuming that Earth's upper mantle is composed of two layers: the lower one, the asthenosphere, being adiabatic (convection controls heat transport); and the upper one, the lithosphere, being diffusive (diffusion dissipates heat). The electrical and seismic discontinuities mapped worldwide supposedly mark these boundaries, but the magmatic processes at the $\mathrm{LAB}$ and their geophysical visibility remain debated. The analysis provided in this chapter shows that several types of incipient melting can produce high mantle ECs. These melting processes can be lithospheric or asthenospheric, and therefore geophysical discontinuities may not image the LAB, but rather illuminate the dynamics of melting and melt transfers in the region of the LAB. Furthermore, geochemical observations have long defined the LAB as a movable boundary; that is to say, melt productions, melt infiltrations, and mantle metasomatism can cause major modifications of lithospheric roots.

Anomalous EC and regions with low seismic velocities have been mapped in many mantle region. ${ }^{22,23,77,79,80}$ A broadly distributed LVZ beneath oceanic domains is deduced from large-scale surveys, ${ }^{23,25}$ but the magnitudes of the velocity decreases locally vary. Beneath cratons, no such LVZ is observed. ${ }^{26}$ After the Mantle ELectromagnetic and Tomography (MELT) experiment that imaged the mantle beneath the ultrafast East Pacific Rise, ${ }^{77}$ several surveys have investigated quieter geodynamic settings hoping for more conventional geophysical signals, but high conductivities and low seismic velocities have often been observed. ${ }^{23}$ The recently investigated NoMelt $\operatorname{area}^{27}$ (70 My old oceanic plates) provides the first geophysical survey identifying no anomalous conductivity and a weak LVZ. If mantle melting is one of the ingredients causing geophysical anomalies, why does such an area exist?

\subsubsection{Manifold Types of Mantle Convection Fuel Incipient Melting}

The driving force of melt production is mantle convection, which produces decompression melting. There are sound geodynamic reasons to argue that decompression melting does not only occur where hot spot volcanoes pierce the surface: the inward mass transfers associated with slab sinking must be compensated by an upward flow being broadly distributed and probably more pronounced beneath oceanic basins. ${ }^{16}$ The rate at which this upward mantle flow occurs should not exceed the melt velocities described in Figure 7.10 (i.e. $\leq 1 \mathrm{~cm} \mathrm{yr}^{-1}$ ), except in large plumes such as Hawaii. ${ }^{76}$ Clearly, convections, decompressions, incipient melting, and melt extractions must occur in many regions 
of Earth's mantle. Convection-related decompression melting must fuel the LAB where upwelling occurs. Where mantle upwelling does not occur, a source of incipient melts simply does not exist. It is not completely clear whether this vision can explain the distribution of mantle geophysical anomalies. ${ }^{23}$ Furthermore, if high EC can be explained by incipient melts, it remains unclear whether the same process could explain the low Swave velocities in the asthenosphere.

\subsection{Limits to Knowledge and Unknowns}

What is the role of partial melting in the LVZ? Grain size and temperature distributions in the solid mantle may be accounted for by the LVZ, ${ }^{81}$ but a recent experimental survey suggests a key role is played by incipient melting. ${ }^{82}$ Melting is also an attractive model to account for the radial seismic anisotropy ${ }^{23}$ of the LVZ. Yet the classical theories of melt equilibrium distribution ${ }^{68}$ have been developed that predict that several volume percentage points of melt are required to significantly reduce seismic wave velocities. ${ }^{83}$ This is at odds with recent experimental measurements ${ }^{82}$ revealing that $<1 \%$ melts drastically reduce $\mathrm{S}$ and P-wave velocities.

Can the LVZ be a low-viscosity zone and can it play a role in the development of plate tectonics? The question is asked by Holtzman, ${ }^{69}$ who tentatively responded by a "yes it can." If minute amounts of melt can wet the mantle grain boundaries and impact largescale geophysical properties such as EC and seismic wave velocities, they may well affect the viscosity of the mantle. If diffusion creep is the mechanism of deformation in such systems, the tremendous diffusion properties of $\mathrm{CO}_{2}$-rich melts demand an assessment of their impact on mantle viscosity. If the LVZ is indeed a low-viscosity zone, it certainly facilitates the motion of plates as suggested by geodynamic models, ${ }^{84}$ and the conjunction of there being no observed LVZ beneath cratons and the relatively slow motion of cratons in comparison to younger plates speaks to a link between the magnitude of the LVZ and the velocity of the overlying plate.

Is there a continuous process from the metasomatic rejuvenation of cratonic roots to the deployment of the LVZ? ${ }^{2}$ The chain of processes, broadly named rejuvenation, involve a combination of mechanical, thermal, chemical, and mineralogical processes. ${ }^{2}$ How does melt ascend? Certainly via a combination of dikes and porous flows, but can we fit this within a proper petrological framework? The first numerical attempts were recently conducted. ${ }^{19}$ Additional efforts are expected.

\section{Acknowledgments}

The authors acknowledge funding from the European Research Council (ERC project \#279790), the French National Research Agency (ANR project \#2010 BLAN62101), and the South African DST/NRF Research Chairs Initiative (Geometallurgy; Fanus Viljoen \#64779). This is Laboratory of Excellence ClerVolc contribution 325. 


\section{Questions for the Classroom}

1 What is the difference between incipient melting and partial melting of the mantle?

2 What is the nature of the produced melts and what are their physical properties?

3 What is the link between the atomic structure and the physical properties of these incipient melts?

4 Which effects could other volatile elements like $\mathrm{S}$ (very redox sensitive), $\mathrm{F}, \mathrm{Cl}$, and B have on the chemical-physical properties of Earth's mantle and on the dynamics of incipient melting?

5 Why can incipient melts barely rise above $60 \mathrm{~km}$, which is the depth at which the pressure is $\sim 2 \mathrm{GPa}$ ?

6 What is the LAB? Can we observe it by geophysical means? What are the geophysical observables?

7 Why can or cannot the LVZ be straightforwardly attributed to partial melting?

8 Is there a unique solution to account for by high EC layers in the mantle?

9 Why can incipient melting be accounted for by EC?

10 Why are some considerations of melt mobility needed in order to interpret high mantle conductivity?

11 What is the geodynamic process that causes incipient melting?

12 Where should we then (not) observe high EC near the LAB?

\section{References}

1. Wallace, M.E. \& Green, D.H., An experimental determination of primary carbonatite magma composition. Nature 335, 343-346 (1988).

2. Aulbach, S., Massuyeau, M., \& Gaillard, F., Origins of cratonic mantle discontinuities: a view from petrology, geochemistry and thermodynamic models. Lithos 268271, 364-382 (2017).

3. Dasgupta, R. et al., Carbon-dioxide-rich silicate melt in the Earth's upper mantle. Nature 493, 211-215 (2013).

4. O'Reilly, S.Y. \& Griffin, W.L., The continental lithosphere-asthenosphere boundary: can we sample it? Lithos 120, 1-13 (2010).

5. Hammouda, T. \& Keshav S., Melting in the mantle in the presence of carbon: review of experiments and discussion on the origin of carbonatites. Chem. Geol. 418, 171-188 (2015).

6. Tappe, S. et al., Craton reactivation on the Labrador Sea margins: ${ }^{40} \mathrm{Ar} /{ }^{39} \mathrm{Ar}$ age and $\mathrm{Sr}-\mathrm{Nd}-\mathrm{Hf}-\mathrm{Pb}$ isotope constraints from alkaline and carbonatite intrusives. Earth Planet. Sci. Lett. 256, 433-454 (2007).

7. Dasgupta, R., Volatile bearing partial melts beneath oceans and continents - where, how much, and of what compositions? Am. J. Sci. 318, 141-165 (2018).

8. Coltorti, M.C. et al., Carbonatite metasomatism of the oceanic upper mantle: evidence from clinopyroxenes and glasses in ultramafic xenoliths of Grande Comore, Indian Ocean. J. Petrol. 40, 133-165 (1999).

9. Pilet, S., Baker, M.B., \& Stolper, E.M., Metasomatized lithosphere and the origin of alkaline lavas. Science 320, 916-919 (2008). 
10. Pinto, L.G.R. et al. Magnetotelluric deep soundings, gravity and geoid in the south São Francisco craton: geophysical indicators of cratonic lithosphere rejuvenation and crustal underplating. Earth Planet. Sci. Lett. 297, 423-434 (2010).

11. Hirano, N. et al., Volcanism in response to plate flexure. Science 313, 1426-1428 (2006).

12. Wyllie, P.J. \& Huang, W.L., Carbonation and melting reactions in the system $\mathrm{CaO}-$ $\mathrm{MgO}-\mathrm{SiO}_{2}-\mathrm{CO}_{2}$ at mantle pressures with geophysical and petrological applications. Contrib. Mineral. Petrol. 54, 79-107 (1976).

13. Taylor, W.R. \& Green, D.H., Measurement of reduced peridotite-C-O-H solidus and implications for redox melting of the mantle. Nature 332, 349-352 (1988).

14. Stagno, V., Ojwang, D.O., McCammon, C.A., \& Frost, D.J., The oxidation state of the mantle and the extraction of carbon from Earth's interior. Nature 493, 84-88 (2013).

15. Le Voyer, M., Kelley, K.A., Cottrell, E., \& Hauri, E.H., Heterogeneity in mantle carbon content from $\mathrm{CO}_{2}$-undersaturated basalts. Nat. Commun. 8, 14062 (2017).

16. Morency, C., Doin, M.-P., \& Dumoulin, C., Three-dimensional numerical simulations of mantle flow beneath mid-ocean ridges. J. Geophys. Res. Solid Earth 110, 344-356 (2005).

17. Ballmer, M.D., van Hunen, J., Ito, G., Tackley, P.J., \& Bianco, T.A., Non-hotspot volcano chains originating from small-scale sublithospheric convection. Geophys. Res. Lett. 34, L23310 (2007).

18. French, S., Lekic, V., \& Romanowicz, B., Waveform tomography reveals channeled flow at the base of the oceanic asthenosphere. Science 342, 227-230 (2013).

19. Keller, T. \& Katz, R.F., The role of volatiles in reactive melt transport in the asthenosphere. J. Petrol. 57, 1073-1108 (2016).

20. Eggler, D.H., Does $\mathrm{CO}_{2}$ cause partial melting in the low-velocity layer of the mantle? Geology 4, 69-72 (1976)

21. Gaillard, F. et al., Carbonatite melts and electrical conductivity in the asthenosphere. Science 322, 1363-1365 (2008).

22. Naif, S., Key, K., Constable, S., \& Evans R.L., Melt-rich channel observed at the lithosphere-asthenosphere boundary. Nature 495, 356-359 (2013).

23. Kawakatsu, H. \& Utada, H., Seismic and electrical signatures of the lithosphereasthenosphere system of the normal oceanic mantle. Ann. Rev. Earth Planet. Sci. 45, 139-167 (2017).

24. Rychert, C.A., Laske, G., Harmon, N., \& Shearer, P.M., Seismic imaging of melt in a displaced Hawaiian plume. Nat. Geosci. 6, 657-660 (2013)

25. Schmerr, N., The Gutenberg discontinuity: melt at the lithosphere-asthenosphere boundary. Science 380, 1480-1483 (2012).

26. Eaton, D.W. et al., The elusive lithosphere-asthenosphere boundary (LAB) beneath cratons. Lithos 109, 1-22 (2009).

27. Sarafian, E. et al., The electrical structure of the central Pacific upper mantle constrained by the NoMelt experiment. Geochem. Geophys. Geosyst. 16, 1115-1132 (2015).

28. Hirschmann, M., Tenner, T., Aubaud, C., \& Withers, A.C., Dehydration melting of nominally anhydrous mantle: the primacy of partitioning. Phys. Earth Planet. Inter. 176, 54-68 (2009).

29. Massuyeau, M., Gardés, E., Morizet, Y., \& Gaillard, F., A model for the activity of silica along the carbonatite-kimberlite-mellilitite-basanite melt compositional joint. Chem. Geol. 418, 206-216 (2015).

30. Hirschmann, M.M., Partial melt in the oceanic low velocity zone. Phys. Earth Planet. Inter. 179, 60-71 (2010). 
31. McKenzie, D., Jackson, J., \& Priestley, K., Thermal structure of oceanic and continental lithosphere. Earth Planet. Sci. Lett. 233, 337-349 (2005).

32. Burgos, G. et al., Oceanic lithosphere-asthenosphere boundary from surface wave dispersion data. J. Geophys. Res. Solid Earth 119, 1079-1093 (2014).

33. Sifré, D. et al., Electrical conductivity during incipient melting in the oceanic lowvelocity zone. Nature 509, 81-85 (2014).

34. Mysen, B.O. \& Richet, P., Silicate Glasses and Melts: Properties and Structure. Elsevier, Amsterdam (2005).

35. Jones, A.P., Genge, M., \& Carmody, L., Carbonate melts and carbonatites. Rev. Mineral. Geochem. 75, 289-322 (2013).

36. Desmaele, E., Physico-chemical properties of molten carbonates by atomistic simulations. PhD thesis, Sorbonne University (2017).

37. Vuilleumier, R., Seitsonen, A., Sator, N., \& Guillot, B., Structure, equation of state and transport properties of molten calcium carbonate $\left(\mathrm{CaCO}_{3}\right)$ by atomistic simulations. Geochim. Cosmochim. Acta 141, 547-566 (2014).

38. Vuilleumier, R., Seitsonen, A.P., Sator, N., \& Guillot, B., Carbon dioxide in silicate melts at upper mantle conditions: insights from atomistic simulations. Chem. Geol. 418, 77-88 (2015).

39. Dufils, T., Sator, N., \& Guillot, B., 2018. Properties of planetary melts by molecular dynamics simulation. Chem. Geol. 493, 298-315 (2018).

40. Guillot, B. \& Sator, N., Carbon dioxide in silicate melts: a molecular dynamics simulation study. Geochim. Cosmochim. Acta 75, 1829-1857 (2011).

41. Moussallam, Y. et al., The molecular structure of melts along the carbonatite-kimberlite-basalt compositional joint: $\mathrm{CO}_{2}$ and polymerisation. Earth Planet. Sci. Lett. 434, 129-140 (2016).

42. Morizet, Y., Florian, P., Paris, M., \& Gaillard, F., ${ }^{17} \mathrm{O}$ NMR evidence of free ionic clusters $\mathrm{Mn}^{+} \mathrm{CO}_{3}{ }^{2-}$ in silicate glasses: precursors for carbonate-silicate liquids immiscibility. Am. Mineral. 102, 1561-1564 (2017)

43. Brooker, R.A. \& Kjarsgaard, B.A., Silicate-carbonate liquid immiscibility and phase relations in the system $\mathrm{SiO}_{2}-\mathrm{Na}_{2} \mathrm{O}-\mathrm{Al}_{2} \mathrm{O}_{3}-\mathrm{CaO}-\mathrm{CO}_{2}$ at $0.1-2.5 \mathrm{GPa}$ with applications to carbonatite genesis. J. Petrol. 52, 1281-1305 (2011).

44. Novella, D. et al. Melting phase relations of model carbonated peridotite from 2 to 3 $\mathrm{GPa}$ in the system $\mathrm{CaO}-\mathrm{MgO}-\mathrm{Al}_{2} \mathrm{O}_{3}-\mathrm{SiO}_{2}-\mathrm{CO}_{2}$ and further indication of possible unmixing between carbonatite and silicate liquids. J. Geophys. Res. Solid Earth 119, 2780-2800 (2014).

45. Morizet, Y. et al., Towards the reconciliation of viscosity change and $\mathrm{CO}_{2}$-induced polymerization in silicate melts. Chem. Geol. 458, 38-47 (2017).

46. Liu, Q. \& Lange, R.A., New density measurements on carbonate liquids and the partial molar volume of the $\mathrm{CaCO}_{3}$ component. Contrib. Mineral. Petrol. 146, 370-381 (2003).

47. Bouhifd, M.A., Whittington, A.G., \& Richet, P., Densities and volumes of hydrous silicate melts: new measurements and predictions. Chem. Geol. 418, 40-50 (2015).

48. Jing, Z. \& Karato, S., Compositional effect on the pressure derivatives of bulk modulus of silicate melts. Earth Planet. Sci. Lett. 272, 429-436 (2008).

49. Sakamaki, T., Density of hydrous magma. Chem. Geol. 475, 135-139 (2017).

50. Ghosh, S. et al., Stability of carbonated magmas at the base of the Earth's upper mantle. Geophys. Res. Lett. 34, L22312 (2007).

51. Sakamaki, T. et al., Density of carbonated peridotite magma at high pressure using an X-ray absorption method. Am. Mineral. 96, 553-557 (2011). 
52. Duncan, M.S. \& Agee, C.B., The partial molar volume of carbon dioxide in peridotite partial melt at high pressure; Earth Planet. Sci. Lett. 312, 429-436 (2011).

53. Ghosh, D.B., Bajgain, S.K., Mookherjee, M., \& Karki, B.B. Carbon-bearing silicate melt at deep mantle conditions. Sci. Rep. 7, 1-5 (2017).

54. Genge, M.J., Price, G.D., \& Jones, A.P. Molecular dynamics simulations of $\mathrm{CaCO}_{3}$ melts to mantle pressures and temperatures: implications for carbonatite magmas. Earth Planet. Sci. Lett. 131, 225-238 (1995).

55. Dobson, D.P. et al., In-situ measurement of viscosity and density of carbonate melts at high pressure. Earth Planet. Sci. Lett. 143, 207-215 (1996).

56. Kono, Y. et al., Ultralow viscosity of carbonate melts at high pressures. Nature Commun. 5, 5091 (2014).

57. Sifré, D., Hashim, L., \& Gaillard, F., Effects of temperature, pressure and chemical compositions on the electrical conductivity of carbonated melts and its relationship with viscosity. Chem. Geol. 418, 189-197 (2015).

58. Hammouda, T. \& Laporte, D., Ultrafast mantle impregnation by carbonatite melts. Geology 28, 283-285 (2000).

59. Sakamaki, T. et al., Ponded melt at the boundary between the lithosphere and asthenosphere. Nat. Geosci. 6, 1041-1044 (2013).

60. Karato, S., The role of hydrogen in the electrical conductivity of the upper mantle. Nature 347, 272-273 (1990).

61. Gardés, E., Gaillard, F., \& Tarits, P., Comment to "High and highly anisotropic electrical conductivity of the asthenosphere due to hydrogen diffusion in olivine" by Dai and Karato [Earth Planet. Sci. Lett. 408 (2014) 79-86]. Earth Planet. Sci. Lett. 427, 296-299, (2015).

62. Ni, H., Keppler, H., \& Behrens, H., Electrical conductivity of hydrous basaltic melts: implications for partial melting in the upper mantle. Contrib. Mineral. Petrol. 162, 637-650 (2011).

63. Yoshino, T., Laumonier, M., McIsaac, E., \& Katsura, T., Electrical conductivity of basaltic and carbonatite melt-bearing peridotites at high pressures: implications for melt distribution and melt fraction in the upper mantle. Earth Planet. Sci. Lett. 295, 593-602 (2010)

64. Yoshino, T. et al., Electrical conductivity of partial molten carbonate peridotite. Phys. Earth Planet. Inter. 194-195, 1-9 (2012).

65. Yoshino, T., Gruber, B., \& Reinier, C., Effects of pressure and water on electrical conductivity of carbonate melt with implications for conductivity anomaly in continental mantle lithosphere. Phys. Earth Planet. Inter. 281, 8-16 (2018)

66. Hunter, R.H. \& McKenzie, D., The equilibrium geometry of carbonate melts in rocks of mantle composition. Earth Planet. Sci. Lett. 92, 347-356 (1989).

67. Watson, E.B., Brenan, J.M., \& Baker, D.R., Distribution of fluids in the continental mantle, in Menzies, M.A., ed., Continental Mantle: Oxford Monographs on Geology and Geophysics. Oxford University Press, Oxford, 111-125 (1990).

68. von Bargen, N. \& Waff, H.S., Permeabilities, interfacial areas and curvatures of partially molten systems: results of numerical computations of equilibrium microstructures. J. Geophys. Res. 91, 9261-9276 (1986).

69. Holtzman, B.K., Questions on the existence, persistence, and mechanical effects of a very small melt fraction in the asthenosphere, Geochem. Geophys. Geosyst. 17, 470-484 (2016).

70. Minarik, W.G. \& Watson, E.B., Interconnectivity of carbonate melt at low melt fraction. Earth Planet. Sci. Lett. 133, 423-437 (1995). 
71. Laumonier, M. et al., Experimental determination of melt interconnectivity and electrical conductivity in the upper mantle. Earth Planet. Sci. Lett. 463, 286-297 (2017).

72. Mu, S. \& Faul, U.H., Grain boundary wetness of partially molten dunite. Contrib. Mineral. Petrol. 171, 40 (2016).

73. Miller, K.J., Montési, L.G.J., \& Zhu, W-1., Estimates of olivine-basaltic melt electrical conductivity using a digital rock physics approach. Earth Planet. Sci. Lett. 432, 332-341 (2015).

74. Faul, U., Melt retention and segregation beneath mid-ocean ridges. Nature 410, 920-923 (2001).

75. Tada, N. et al., Electromagnetic evidence for volatile-rich upwelling beneath the society hotspot, French Polynesia. Geophys. Res. Lett. 43, 12021-12026 (2016).

76. Ballmer, M.D., Ito, G., van Hunen, J., \& Tackley, P.J., Spatial and temporal variability in Hawaiian hotspot volcanism induced by small-scale convection. Nat. Geosci. 4, 457-460 (2011).

77. Evans, R.L. et al., Geophysical controls from the MELT area for compositional controls on oceanic plates, Nature 437, 249-252 (2005).

78. Okumura, S. \& Hirano, N., Carbon dioxide emission to Earth's surface by deep-sea volcanism. Geology 41, 1167-1170 (2013).

79. Tada, N., Tarits, P., Baba, K., Utada, H., Kasaya, T., \& Suetsugu, D., Electromagnetic evidence for volatile-rich upwelling beneath the society hotspot, French Polynesia. Geophys. Res. Lett. 43, 12021-12026 (2016).

80. Baba, K., Utada, H., Goto, T.-N., Kasaya, T., Shimizu, H., \& Tada, N., Electrical conductivity imaging of the Philippine Sea upper mantle using seafloor magnetotelluric data. Phys. Earth Planet. Inter. 183, 44-62 (2010).

81. Jackson, I. \& Faul, U.H., Grain size-sensitive viscoelastic relaxation in olivine: towards a robust laboratory-based model for seismological application. Phys. Earth Planet. Inter. 183, 151-163 (2010).

82. Chantel, J. et al., Experimental evidence supports mantle partial melting in the asthenosphere. Sci. Adv. 2, e1600246 (2016).

83. Wimert, J. \& Hier-Majumder, S., A three-dimensional microgeodynamic model of melt geometry in the Earth's deep interior. J. Geophys. Res. 117, B04203 (2012).

84. Höink, T., Jellinek, A.M., \& Lenardic, A. Viscous coupling at the lithosphereasthenosphere boundary. Geochem. Geophys. Geosyst. 12, Q0AK02 (2011).

85. Gardés, E., Gaillard, F., \& Tarits, P., Toward a unified hydrous olivine electrical conductivity law. Geochem. Geophys. Geosyst. 15, 4984-5000 (2014). 